Perikamana, A. Ayer, S. K., Beauregard, M. A. and Alsafouri, S. (2017). "Development of Collaborative Process Mapping Activity to Improve Students' BIM Process Mapping Understanding”. In: LC3 2017: Volume I - Proceedings of the Joint Conference on Computing in Construction (JC3), July 4-7, 2017, Heraklion, Greece, pp. 989-995. DOI: https://doi.org/10.24928/JC3-2017/0061.

\title{
DEVELOPMENT OF A COLLABORATIVE PROCESS MAPPING ACTIVITY TO IMPROVE STUDENTS' BIM PROCESS MAPPING UNDERSTANDING
}

\author{
Aparna Perikamana ${ }^{1}$, Steven K. Ayer ${ }^{2}$, Michael A. Beauregard ${ }^{3}$ and Suleiman Alsafouri ${ }^{4}$
}

\begin{abstract}
The use of BIM has become increasingly common, which has led to a growing demand for construction professionals with BIM knowledge and skills. BIM education is a solution to meet this growing need. Prior research suggests students associate BIM with a software solution rather than as a process illustrating a need to modify the current educational paradigms. This paper explores a pedagogical approach to developing BIM process planning skills among construction students. The research extends the findings of prior work that tasked students with developing process maps in a peer-reviewed context. This current iteration of the research explores the use of a collaborative, team-based, activity to generate Level 1 and Level 2 process maps, as defined by a previously published BIM Project Execution Planning Guide. The students were asked to create the process maps individually at first, and then again in groups of three. Pre- and post-questionnaires were given to analyse the students' perception of their knowledge. The primary objective of the research was to elicit a perception based response with respect to (i) students' ability to create a process map, (ii) enhancing the learning process, and (iii) students' perception about their own knowledge of the BIM execution process. In addition to perception based questions, the authors made an observational analysis of completed process maps. The students' confidence in their ability in creating a process mapping dialogue box appears to have increased because of the activity. However, the students' perception of their ability to arrange the activities in sequence and parallel and the ability to create process map did not have any significant improvement. Based on the questionnaires and the suggestions given, it can be concluded that in both activities, the students had difficulties understanding the process mapping language. Future research may address the implementation of new pedagogical methods, incorporating the findings identified in this research thereby improving the measurable outcome of the students understanding of Process Mapping specific to BIM implementation.
\end{abstract}

Keywords: BIM, BIM Process Mapping, BIM Education, Collaborative Activity

\section{INTRODUCTION}

Building Information Modelling (BIM) can be defined as the development and usage of digital representations of buildings that include both physical and functional

1 Graduate Research Assistant, Del E. Webb School of Construction, Arizona State University, Arizona, USA aperikam@asu.edu

2 Assistant Professor, Del E. Webb School of Construction, Arizona State University, Arizona, USA Steven.Ayer@asu.edu

3 Graduate Research Associate, Del E. Webb School of Construction, Arizona State University, Arizona, USA Michael.Beauregard@asu.edu

4 Graduate Research Associate, Del E. Webb School of Construction, Arizona State University, Arizona, USA Suleiman.Alsafouri@asu.edu 
characteristics (National Institute of Building Sciences 2007). BIM represents a new paradigm within the Architecture, Engineering and Construction (AEC) industry that encourages integration of all stakeholders on a project (Azhar 2011). The use of BIM has become increasingly common and will continue to grow, leading to increased demand for construction professionals with BIM knowledge and skills. BIM education is a solution to accelerate the BIM learning curve, thus providing companies with readymade BIM experts when students graduate (Pikas 2013). Recognition of the importance of a rigorous BIM course as a primary and fundamental component of an academic curriculum has led to the introduction of BIM courses in many universities programs.

A fourth-year project management course, "CON 453 - Project Management 1" offered at Arizona State University (ASU) was utilized for this study. Students from both Construction Management and Construction Engineering disciplines comprised the student body of CON 453. The curriculum of this course integrates BIM planning and execution with multiple construction delivery methods to develop the managerial capabilities of the student. In recent years, BIM Project Execution Planning (PxP) (CIC, 2010) was added to the course curriculum to enable students to define processes to support successful BIM implementation. Various teaching methods were introduced to enhance the students' understanding of BIM PxP development over the course of several years (Beauregard et. al. 2016). The previous method had no significant impact on students' perception of their own learning process. Additionally, it was observed that students often did not demonstrate their ability to use Business Process Mapping Notation (BPMN) symbols.

This paper is an expansion of prior research to better understand process mapping education (Beauregard et. al. 2016). In Spring 2016 the authors introduced a new collaborative approach to the BIM-based class activity. The hypothetical building project and process mapping requirements aligned to prior years' studies. When students completed an individual Level 1 and Level 2 process maps, they were asked to collaboratively develop Level 1 and Level 2 process maps in groups of three.

This paper focuses on analysing the effectiveness of this new teaching method and suggests modifications for future improvement. To analyse the effectiveness of the activity, the student-developed process maps, and pre- and post-questionnaires were explored. This analysis will address the following research questions:

1. Are collaborative process mapping activities more effective at developing the students' ability to construct BIM process maps?

2. Are students successful at demonstrating their ability to communicate using process mapping language from this pedagogical approach?

3. How do students perceive the value of this pedagogical strategy for their own BIM process mapping education?

\section{BACKGROUND}

Building Information Modeling (BIM) has found its value in various stages of the construction process (Azhar 2011). It can provide value in cost estimating, construction sequencing, conflict, interference and collision detection, forensic analysis and facilities management (Azhar 2011). As the importance of BIM is widely recognized in the AEC industry, it is essential for the new generation of construction management professionals to learn BIM while undertaking studies at universities (Wang 2014). BIM education can 
help students understand the complexity of construction projects from both the product and process perspectives (Sacks 2013).

A BIM course can enable students to (1) define BIM, (2) describe workflow in using BIM in the building life cycle, (3) describe the process of model-based cost estimating, (4) perform 4D simulations, (5) apply BIM to reduce error and change orders in capital projects, (6) evaluate the use of 3D point clouds to support construction and asset management, (7) perform building energy performance simulations, and (8) evaluate and communicate ideas related to the use of BIM in the building life cycle (Wang 2014). Even though BIM education is common, one of the major issues observed is a lack of understanding of strategic BIM implementation (Wu et.al 2013). In academic settings, BIM is often recognized as simply digital design, which does not directly incorporate learning tasks related to developing a BIM process for implementation on a project (Wang 2014). Thus, enhancing the students' understanding of the BIM process has the potential of adding real and measurable value to the students' professional career. This work focuses on enhancing the learning process of BIM Project Execution Planning (PxP) through an activity related to process mapping.

A process map is defined as a visual or graphical depiction of a process flow (Cooper et al. 2013). A process map is created using Business Process Mapping Notation (BPMN) symbols. The process map allows the team to understand the overall BIM process, identify the information exchanges that will be shared between multiple parties, and clearly define the various processes to be performed for the identified BIM Uses (CIC 2010). The process map will also serve as the basis for identifying other important implementation topics, including contract structure, BIM deliverable requirements, information technology infrastructure, and selection criteria for future team members (CIC 2010). There are two ways to map the project execution process, (i) Level 1: BIM overview map and (ii) Level 2: Detailed BIM Use process map (CIC 2010). In short, a well-written process map is an effective tool for communicating the overall BIM implementation to students. The goal of this pedagogical study is to measure students' ability to demonstrate their understanding of BIM PxP content through a process mapping activity.

\section{METHODOLOGY}

BIM execution planning was added to the course curriculum of CON 453 as a tool for providing students with an in-depth understanding of implementing BIM on a project. Students attended two seventy-five minute lectures and one two-hour lab session every week. Lectures focused on the role of BIM in the construction industry while lab sessions offered a practical experience using BIM software. Additionally, the development of a $\mathrm{BIM} \mathrm{PxP}$ was introduced to the course curriculum to enhance the students' ability to manage BIM on projects. This semester-long project requires students to: use BIM software applications; and plan for BIM implementation through their PxP. This newly introduced BIM process mapping activity was developed to aid students in their project.

\subsection{Pre-Activity Lecture:}

Prior to completing the BIM process mapping activity for this research, students were introduced to BIM planning concepts through a class lecture. This lecture included content related to process mapping as a critical component of project execution planning. While the lecture only provided a single introduction to this concept, it helped to provide 
Development of Collaborative Process Mapping Activity to Improve Students' BIM Process Mapping Understanding

context to the students when completing the subsequent process mapping activity for this research.

\subsection{Pre-Activity Assessments:}

An initial questionnaire was given to the students prior to the start of the activity, along with an informed consent sheet in accordance with the Institutional Review Board (IRB) requirements. The questionnaire consisted of two targeted areas of understanding. The first section, general student information, gathered basic information about the students such as construction industry experience and experience in creating BIM process maps.

The second section addressed the students' perception regarding their knowledge of BIM and the process of mapping to include their ability to sequence BIM activities, the importance of process map in communication, and their ability to create a coherent process map. Although every student was required to participate anonymously in the activity for class, the decision to include or not include their response for research was voluntary.

\subsection{Process Mapping Activity:}

Upon completion of the pre-activity assessment, students were introduced to the hypothetical construction project for which they would need to plan for BIM. A campus building that houses their department was chosen for this because students had a familiarity with the building. Additionally, several BIM uses were provided to the students as required uses for which they would need to plan. After they were introduced to the hypothetical activity, students were provided with a blank process map. The subsequent activity required students to create a Level 1 map for this hypothetical project and a Level 2 process map for 4D modeling for the project.

The activity was first completed individually and then completed again in groups of three. During the individual work, three different colored pens (blue, black and red) were distributed among the students. They were asked to define a Level 1 and Level 2 process maps on the template provided using their colored pen on their own. Subsequently, during the group activity, students formed teams of three with a student who was assigned one of each colored pen. These groups were asked to create a Level 1 and Level 2 process map collaboratively. During this activity, students used the same colored pen as they had in the individual activity, which allowed the researchers to identify what portions of the collaborative process map were added by which student.

\subsection{Post-Activity Assessments:}

Upon completion of the activity, post-assessment questionnaires were distributed to the students. This second questionnaire elicited responses from the students related to their perception of the learning process and their own knowledge about related topics. The questions included some similar questions to those included in the pre-activity questionnaire along with questions regarding students' interest and confidence in creating a Level 1 and Level 2 process map and about students' perception of their understanding of BIM process mapping. The common questions that were included on both pre- and post-activity questionnaires included:

a) Rate your ability to create process mapping dialogue box

b) Rate your ability to arrange activities in sequence

c) Rate your ability to create a Level 1 process map

d) Rate your ability to create Level 2 process map 
In addition to the Likert-scale questions, four open-ended questions were also provided to elicit student feedback about this activity.

\subsection{Data Analysis:}

The data analysis was based on students' perception of their own knowledge and based on the observations made by the authors. As a part of this assessment, 4 paired questions related to students' own perception of their ability to create Level 1 and 2 process maps and parallel and sequential arrangement of activities were considered. A two-tail t-test was used to analyze the data. Only the responses from students who consented to use their response for research were used for the analysis. The responses provided to the preactivity questionnaire and post-activity questionnaire were compared to illustrate any shift in the students' perception about gaining knowledge through this activity.

The group process maps were analysed to study the collaboration among the group members. This was done by studying the different ink colours present on the process maps to determine whether the students could collaboratively illustrate their ideas in the process map. Process maps were analysed based on the usage of BPMN language, identification of stakeholders, and definition of communication that would be required across the swim lanes of the process maps. Conclusions were generated based on the results obtained from the analysis.

\section{RESULTS}

For the process mapping activity, 35 students consented to allow their responses be used for research having completed all assessments during the Spring 2016 semester. The class was comprised of 8 juniors and 32 seniors. The average industry experience of the class was found to be 2.9 years. Of the 35 students, only 3 had not had any industry experience. Only one student had had prior industry experience using BIM.

A two-tail probability distribution approach was used to find the statistical significance of the data. A p-value less than 0.05 for the paired question 'Rate your ability to create process maps' indicates significance at the $95 \%$ confidence level that the students perceived a positive impact on their ability to create Process Mapping Dialogue Box after participating in the process mapping activity. No significant perception shift was observed from among the other paired questions.

The created process maps were analysed by considering the usage of BPMN. Usage of process mapping notations, mentioning of stake holders and communication across the swim lanes were considered during the analysis. There were total 12 groups for the collaboration activity. The number of groups that demonstrated each criterion was observed. The observations in percentage for Spring 2016 semesters are given in Table 1.

Table 1: Evaluation Summary for Collaboration Activity (Spring 2016)

\begin{tabular}{ccc}
\hline Questions & Level 1 & Level 2 \\
\hline Use of BPMN notations & $75 \%$ & $83.33 \%$ \\
Mentioning stake holders & $91.66 \%$ & $50 \%$ \\
Communication across the swim lanes & $50 \%$ & $75 \%$ \\
\hline
\end{tabular}


Development of Collaborative Process Mapping Activity to Improve Students' BIM Process Mapping Understanding

\section{DISCUSSION}

After analysing the pre- and post-activity questionnaires, it was observed that the group activity had an impact on the students' learning process. From pre- and postquestionnaires, it was observed that the students felt that their ability to create a process mapping dialogue box increased upon completion of the activity. However, no observable shift in their perception of their ability to create a level 1 or 2 process map was observed.

The process maps from the peer review activity during Fall 2015 were observed and several findings were observed. First, the stakeholders were not mentioned in most places in the process maps. Secondly, some students accepted the suggestions provided by their peers in the peer-review process, but others did not. In some cases, students noted the reason for incorporating or not accepting peer feedback, which helped to provide context to their thought process. Finally, in the prior implementation, students frequently mentioned a lack of knowledge about the specific BIM use for which they were tasked with planning.

In contrast to peer-reviewed process maps from Fall 2015, most the collaborative process maps from the Spring of 2016 used BPMN symbols (Table 1). It was also observed that stakeholders were mentioned only by a minority of the students. Most of the students were not able to create Level 2 process maps. Many of the provided process maps were left blank during the activity. This can be due to a lack of ability to use BPMN symbols or due to lack of ability to demonstrate their understanding of the BIM process. The lack of knowledge in 3D coordination process was reflected in some of the created process maps.

Some process maps included content in all three pen colours, which indicates a level of collaboration among team members. Other process maps only included a single pen colour. While students may have collaboratively developed these maps, the single pen colour could also mean that one student tended to lead the process map development.

The main observed points led to the conclusion that students found it hard to participate in this activity as they may not have understood the process mapping language. Some of the suggestions obtained from the students include more explanation about process map before the activity, more guidance through each step, and more time for the activity.

There are a few limitations to this research activity. as the conclusions are derived based on a small selected sample and the questionnaire which focuses on the students' perception about their knowledge. There is no valid approach considered to assess the ability of students to demonstrate their understanding about the process map. Students mentioned the time given for the process mapping activity and their understanding about process mapping as limitations in the feedback section.

\section{CONCLUSION}

The process mapping activity conducted in CON 453 in Fall 2015 (peer review activity) and in Spring 2016 (collaboration activity) was considered as a part of this pedagogical study. The pre- and post-activity questionnaires were analyzed for interpreting the students' perception about their knowledge before and after the activity. The process maps were analyzed to determine the students' ability to demonstrate their understanding of process mapping language and their understanding of the BIM process. 
The pre- and post-activity questionnaire responses suggested that the students' perception of their own ability to create process mapping dialogue boxes increased after the activity. Conversely, their perception of their ability to arrange the activities in sequence and parallel and their ability to create process maps did not have any significant improvement. Based on the pre- and post-questionnaire, no significant improvements in the students' perception of their own abilities were observed compared to prior semesters. This can be due to of lack of understanding of the BIM process. Based on the questionnaires and the suggestions given by the students, it can be concluded that in both the activities, the students had a hard time in understanding the process mapping language.

Future studies will be conducted to address the educational shortcomings with the findings of this work. A process mapping activity can be conducted for other BIM uses or other processes that are more easily understood by students. This may help students to grasp process mapping better before trying to plan for complex BIM tasks. Finally, a consistent grading rubric will be developed for analysing the process maps to evaluate shifts in students' abilities during different semesters.

\section{REFERENCES}

Azhar, S. (2011). Building Information Modeling (BIM): Trends, Benefits, Risks, and Challenges for the AEC Industry. Leadership and Management in Engineering, 11(3), pp.241-252.

Beauregard, M., Alsafouri, S. and K. Ayer, S. (2016). Development of a peer-review based activity to improve students BIM process mapping understanding. In: Academic Symposium \& Job task analysis review.

BIM Project Execution Planning Guide by CIC Research Group (2010), Department of Architectural Engineering, The Pennsylvania State University is licensed under a Creative Commons Attribution-Share Alike 3.0 United States License.

Cooper, Tony, and Charlie Moore (2013). "Use Process Mapping to Improve Quality." Chemical Engineering Progress 109 (8): 45-52.

National Institute of Building Sciences, Washington D.C., (2007). United States National Building Information Modeling Standard: Version 1 - Part 1: Overview, Principles, and Methodologies.

Pikas, E., Sacks, R. and Hazzan, O. (2013). Building Information Modeling Education for Construction Engineering and Management. II: Procedures and Implementation Case Study. Journal of Construction Engineering and Management, 139(11), p.05013002.

Sacks, R. and Pikas, E. (2013). Building Information Modeling Education for Construction Engineering and Management. I: Industry Requirements, State of the Art, and Gap Analysis. Journal of Construction Engineering and Management, 139(11), p.04013016.

Wang, L. and Leite, F. (2014). Process-Oriented Approach of Teaching Building Information Modeling in Construction Management. Journal of Professional Issues in Engineering Education and Practice, 140(4), p.04014004.

$\mathrm{Wu}, \mathrm{W}$. and Issa, R. (2014). BIM Education and Recruiting: Survey-Based Comparative Analysis of Issues, Perceptions, and Collaboration Opportunities. Journal of Professional Issues in Engineering Education and Practice, 140(2), p.04013014. 